\title{
Análise da arquitetura tumular do cemitério jardim municipal de Maringá, Estado do Paraná
}

\author{
Analysis of the Tomb Cemetery Municipal Garden of Maringa, state of Parana
}

\author{
Aline Giseli Martim¹, Bruno Luiz Domingos de Angelis², Generoso de Angelis Neto ${ }^{3}$ e \\ Frederico Fonseca da Silva ${ }^{4}$
}

\begin{abstract}
${ }^{1}$ Geógrafa, Especialista em Planejamento Ambiental, Mestre pelo PEU - Programa de Pós-graduação em Engenharia Urbana da UEM - Universidade Estadual de Maringá, PR, Brasil

2. Doutor em Planejamento de Áreas Verdes, Professor e Pesquisador - Universidade Estadual de Maringá, PR, Brasil

${ }^{3}$ Doutor em Geotécnica - UEM, Professor e Pesquisador da UEM - Universidade Estadual de Maringá, PR, Brasil

${ }^{4}$ Doutor em Irrigação e Meio Ambiente - UEM, Professor e Pesquisador do IFPR - Instituto Federal do Paraná, PR, Brasil
\end{abstract}

\section{Resumo}

Partindo-se do pressuposto que o sepultamento de corpos e a sua subsequente decomposição em cemitérios horizontais, pode potencialmente causar a contaminação das águas subterrâneas, o presente trabalho tem por objetivo analisar as características estruturais dos túmulos e a arquitetura tumular do Cemitério Jardim Municipal de Maringá, localizado no Estado do Paraná, a partir da identificação dos diversos modelos de arquitetura tumular ali presentes. Assim, a elaboração deste artigo, ocorreu priorizando o cumprimento dos Decretos Municipal $n^{0}$ 100/1984 e $n^{0}$ 1475/2002, que aprovou o Regulamento do Cemitério Jardim Municipal, além de regulamentar o revestimento e reconstruções de sepulturas presentes no mesmo.

Palavras-chave: Arquitetura Tumular. Cemitério. Legislações. Maringá.

\begin{abstract}
Based on the assumption that the burial of bodies and their subsequent decomposition into horizontal cemeteries can potentially cause contamination of groundwater, this paper aims to analyze the structural characteristics of the tombs and the tombs of architecture Garden Municipal Cemetery of Maringa, located in the Parana State (Brazil), from the identification of different types of architecture. Thus, the preparation of this article was focus on compliance with Municipal Decree $n^{\circ}$ 100/1984 and $n^{\circ}$ 1475/2002 approving the Regulation of Garden City Cemetery, in addition to regulating the coating and reconstructions of tombs in the same.
\end{abstract}

Keywords: Architectural Grave. Cemetery. Laws. Maringa. 


\section{Introdução}

O homem nômade não tinha o costume de enterrar seus mortos, apenas os deixava entrar em decomposição ao ar livre, uma vez que, devido a não convivência com o corpo, por não apresentarem moradia fixa, este não lhe trazia problemas.

A partir do momento que o homem fixa-se em um determinado local, os mortos também se fixam; a priori, acondicionados em cavernas e, posteriormente, em locais específicos próximos a igrejas, quando do surgimento das cidades.

Somente neste momento surge então à preocupação em conservação do corpo e, por consequência, a permanência do ideário humano. Isto é, o surgimento do cemitério como símbolo de continuidade destes mortos.

A palavra cemitério (do grego Koumitérion, de Kmão, eu durmo) designava, a princípio, lugar onde se dorme, quarto, dormitório.

Já segundo Silva et al. (2006), surgidos há mais de 100 mil anos atrás, os cemitérios sempre tiveram a finalidade de alocar corpos. Pelo fato de os cemitérios serem monumentos à memória daqueles que morreram e que os vivos fazem questão de perpetuar ao longo do tempo, este tipo de construção adquiriu a condição de inviolabilidade no que tange a pesquisa científica nos seus diferentes aspectos, sendo, muitas vezes vista com olhares de reprovação.

De acordo com Pacheco e Batelo (2000), foi a partir dos 10 mil anos a.C, que as sepulturas são agrupadas e, assim, aparecem os primeiros cemitérios com túmulos individuais e sepulturas coletivas.

Contudo, foi sob a influência do cristianismo que o termo tomou o sentido de 'campo de descanso até a morte'. Tem como sinônimos: necrópole, carneiro, sepulcrário, campo santo, cidade dos pés juntos e última moradia (ALMEIDA, 2004).

O relacionamento dos homens com a morte, segundo Romanini et al. (2004), é estreita, tendo em vista que, este possui consciência de que a morte esta além de suas forças e com toda a evolução tecnológica por este realizada. Entretanto, o temor e a angústia da morte levam a humanidade à crença da imortalidade, promovendo assim uma aceitação do sobrenatural, do divino, do imortal, características encontradas nas muitas mistificidades que os cemitérios apresentam principalmente no que diz respeito aos símbolos tumulares.

No Brasil, as construções mortuárias (sepulturas, carneiros, jazigos, ossuários) aparecem inicialmente no final do século XIX, no Rio de Janeiro (RJ) e, posteriormente, em São Paulo (SP), espalhando-se por outras cidades do país, inclusive na cidade de Ponta Grossa (PR), mais especificamente no cemitério São José, fundado em 12 de outubro de 1890, onde estas construções apresentam características específicas de um movimento arquitetônico em cemitérios denominados egiptomania.

Cymbalista (2002) complementa a concepção de paisagem e arquitetura tumular quando relata que os cemitérios são como os microcosmos das cidades, nos quais sua paisagem é normatizada e hierarquizada segundo os critérios estabelecidos no século XIX.

De acordo com Matos (2001) há impactos gerados pelos cemitérios na maioria das cidades brasileiras, e mesmo sem a comprovação científica, é visível que os cemitérios foram construídos antes da existência de legislação sobre o assunto (isso onde ela existe).

É notório que entre seus muros, o cemitério apresenta um grande acervo cultural cuja arquitetura sofreu interferências de diferentes povos, raças, origens e culturas, pois nesse espaço considerado santo para muitos povos e religiões ou para os que assim consideram, estão reproduzidos símbolos estabelecidos no mundo dos vivos.

Tal afirmação torna-se verdadeira também no que diz respeito ao Cemitério Jardim Municipal de Maringá, uma vez que, de 1947 (data do primeiro sepultamento catalogado nos livros de registros), até idos de 1984, os sepultamentos eram realizados sem uma padronização, tanto no que se refere à profundidade, comprimento e largura dos lóculos quanto ao sentido.

Desta forma, a verificação da estrutura dos túmulos, bem como da arquitetura tumular do Cemitério Jardim Municipal de Maringá (PR), torna-se importante, uma vez que, ao se analisar os parâmetros legais referentes às legislações vigentes se terão condições de identificar a paisagem

REGET - V. 20, n. 1, jan.- abr. 2016, p.475-486 
construída deste, articulada à natural, bem como, analisar o conjunto de informações ali presentes, com a finalidade de determinar locais de vulnerabilidade quanto ao tipo de planejamento do mesmo.

Os cemitérios, ou necrópoles, são elementos do meio urbano e, como tais, podem ser classificados mediante suas especificidades, como os pontos poluidores, sejam estes pontos analisados tanto pela poluição visual quanto, e hoje principalmente, pela ambiental.

O investimento do supérfluo no túmulo faz parte do processo de diferenciação social, especialmente quando se pretende prestígio para o nome de família (VALADARES, 1972).

Assim, a partir da conceituação de lugar, como extensão do acontecer homogêneo ou do acontecer solidário, na configuração territorial, o presente estudo buscou articular o desenho ambiental, a arquitetura e o paisagismo encontrado no Cemitério Jardim Municipal de Maringá (PR).

\section{DESENVOLVIMENTO}

Essa vulnerabilidade de cunho ambiental pauta-se na análise dos parâmetros legais referentes às seguintes legislações: Resolução 357, de 17 de março de 2005, do Conselho Nacional do Meio Ambiente (BRASIL, 2005), Lei Federal n 6.938, de 31 de agosto de 1981 (BRASIL, 1981) bem como, a norma da CETESB 15.011/1992 e as resoluções 019/2004 (PARANÁ, 2004) e 016/2005 (PARANÁ, 2005), ambas da Secretaria de Estado de Meio Ambiente e Recursos Hídricos do Estado do Paraná, que dispõem sobre o licenciamento ambiental de cemitérios, considerando a necessidade de dar efetividade ao princípio da prevenção contra agentes potencialmente poluidores como o produto da coaliquação ou vulgarmente denominado de necrochorume.

Associado a isso, o que reforça a vulnerabilidade arquitetônica, os Decretos Municipais no 100/1984 (PMM, 1984) e no 1.475/2002 (PMM, 2002), dão as devidas providencias quanto aos procedimentos cabíveis no local, como, definições de divisões de praças, ruas, quadras, dimensionamentos de lotes, sendo estes, sepulturas, carneiros, entre outros, como também o revestimento e reconstrução de sepulturas do mesmo.

Assim, somente a partir do Decreto $n^{\circ}$ 100/1984 (PMM, 1984), foi aprovado o regulamento do Cemitério Jardim Municipal de Maringá, onde são regulamentadas diretrizes quanto a cadastro de utilização do espaço, as divisões deste em praças, ruas, quadras e a divisão destas últimas em lotes ou sepulturas, assim como, à guarda dos sepultamentos e sua identificação adequada.

Desta forma, para verificar a paisagem formada no Cemitério Jardim Municipal, a partir da articulação arquitetura tumular e meio ambiente natural, primou-se por uma metodologia focada na análise minuciosa dos Decretos no 100/1984 (PMM, 1984), e no 1.475/2002 (PMM, 2002), a fim de detectar se as pontuações neles contidas estão condizentes com a constituição física (arruamentos, formatos de praças, construções tumulares) das quadras formadas a partir de 1984.

Segundo Silva (1998), o Cemitério Jardim Municipal fez parte do anteprojeto da cidade, elaborado por Jorge Macedo Vieira. Como em todas as cidades traçadas pela Companhia Melhoramento Norte do Paraná - CMNP.

Caracteristicamente, o cemitério horizontal público do Município de Maringá, está inserido na Região Noroeste do Estado - 3o Planalto Paranaense, mais especificamente na Rua Vereador Primo Monteschio, no 435, Zona 02, e contempla uma área de, aproximadamente, $255.000 \mathrm{~m}^{2}$.

Apresenta como o primeiro registro de sepultamento o Sr. Henrique Peres, falecido aos 80 anos, no dia 07 de junho de 1947. Entretanto, a partir de visitas in loco, a primeira sepultura que pode ser verificada na Figura 1, data do ano de 1951, onde se encontra sepultado um Padre (cujo nome não pode ser identificado) que chegou ao município junto com a atual Companhia Melhoramento do Norte do Paraná.

Tal fato, potencialmente, ocorreu, pois os primeiros sepultamentos eram realizados diretamente no solo e, em virtude de tentativas de se aprimorar o cemitério, perderam-se, não sendo possível à localização de sepulturas como a registrada como sendo a primeira.

Acresça-se que, anteriormente à regulamentação do cemitério pelos Decretos 100/1984 (PMM, 1984) e 1.475/2002 (PMM, 2002), eram realizadas apenas uma catalogação dos sepultamentos, em livros de registros. Contudo, esta catalogação era realizada sem critério uma vez que, na primeira metade do 
livro, onde deveriam estar registrados todos os demais detalhes, principalmente quanto à localização, sepultamentos datados para o período de 1948 a 1952, encontram-se apenas registrado o primeiro sepultamento (1947).

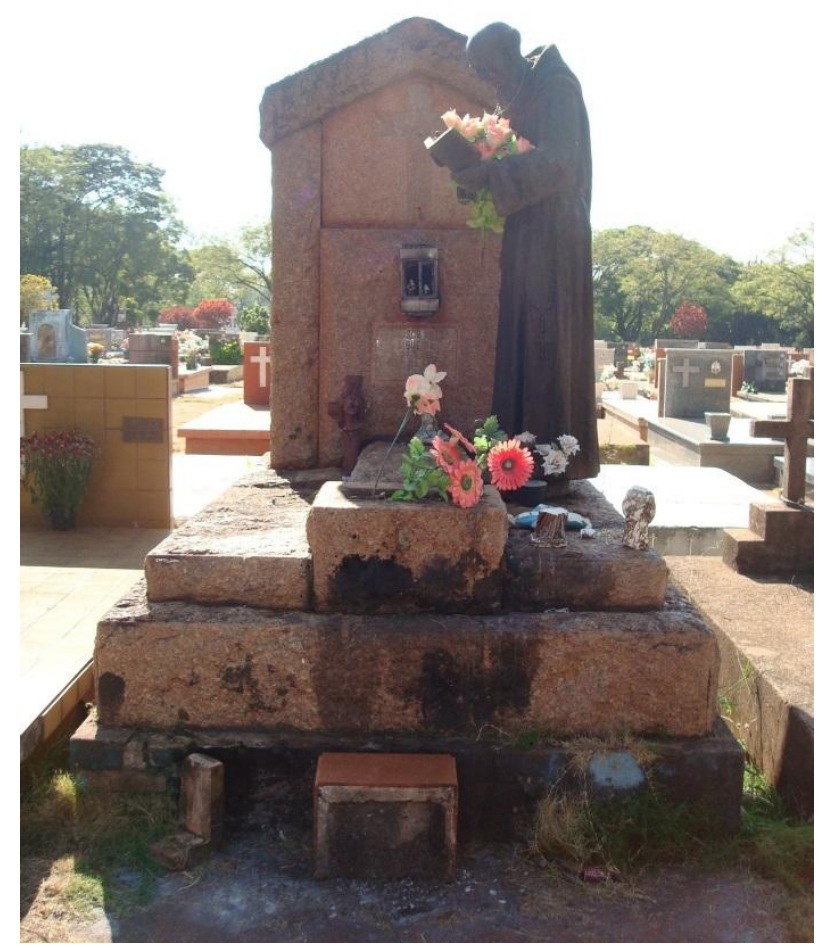

Figura 1. Visualização da sepultura mais antiga do cemitério jardim de Maringá

Fonte: os autores (2012)

Somente no final da década de 1960 e princípio da década de 1970, a fim de manter a historicidade do Cemitério Jardim Municipal, juntamente com a catalogação dos sepultamentos, teve-se início a identificação da quadra e do lote onde os mortos são inumados.

Assim, foi a partir dos Decretos supracitados, que o Cemitério Jardim de Maringá adquiriu uma padronização quanto às suas poucas covas rasas (tipos de "compartimento" destinados aos sepultamentos de corpos: aberta em solo natural) e seus carneiros (cova com paredes laterais de tijolos e revestidas de argamassa, tendo internamente o máximo de dois metros e cinquenta centímetros de comprimento por um metro e cinco centímetros de largura por um metro de profundidade).

Saliente-se, no entanto que, quando o carneiro for duplo, este deverá apresentar cova com paredes laterais de tijolos e revestidas de argamassa, tendo internamente no máximo dois metros e cinquenta centímetros de comprimento, por um metro e cinco centímetros de largura por um metro e dezoito de profundidade, de acordo com o Decreto 100/1984 (PMM, 1984).

Ainda segundo Decreto 100/1984 (PMM, 1984), estes túmulos devem apresentar como descritos em seu Capitulo I, mais especificamente no artigo $4^{\circ}$, as seguintes dimensões: sepultura - cova rasa quando designadas a adultos apresentam dois metros e vinte de comprimento por setenta e cinco centímetros de largura e um metro e setenta centímetros de profundidade; e, quando destinadas a crianças, estas deverão apresentar um metro de comprimento por setenta centímetros de largura e um de profundidade.

O referido Decreto ainda cita que o fundo dos carneiros deve ser coberto com camadas de areia grossa, areia fina e pedra brita antes da urna mortuária ser inumada, para facilitar a drenagem e a filtragem do líquido do necrochorume exalado no processo de decomposição corpórea, no terreno.

No caso dos jazigos, o citado Decreto ainda o caracteriza como cova funerária construída em concreto armado destinada a seis inumações, isto é, seis sepultamentos, apresentando internamente 
dois metros e setenta centímetros de largura por dois metros e oitenta centímetros de profundidade, contemplando ainda seis nichos internos para depósitos de ossos.

Os ossuários coletivos, no entanto, dever apresentar compartimento de dimensões amplas, com paredes em alvenaria, destinadas à guarda de ossos oriundos de exumações onde não há manifestações de interessados em guardá-los em sepulturas, carneiro, jazigos ou ossuários individuais.

Quanto às capelas velórios, estas mediante o Decreto deveriam apresentar-se com cômodos fechados em madeira, independentes entre si, além de serem adaptadas com parâmetros necessários para a utilização em velórios.

O caso do Decreto no 1.475 (PMM, 2002) foi criado para regulamentar o revestimento e reconstruções de sepulturas do Cemitério Jardim Municipal de Maringá, a fim de se padronizar a execução de obras de revestimentos ou até mesmo embelezamento das sepulturas do cemitério. Para tanto, em seus 8 artigos são estabelecidos os critérios quando da execução do revestimento e reconstrução das sepulturas do referido cemitério.

Em seu artigo $1^{\circ}$, mais especificamente em seu segundo parágrafo, fica disposto que o revestimento em cerâmica, para túmulos caracterizados como Simples, Duplos e Jazigos familiares devem ser divididos em quatro partes e uma lápide separada do túmulo medindo 1,30 m de altura por 0,80 m de largura.

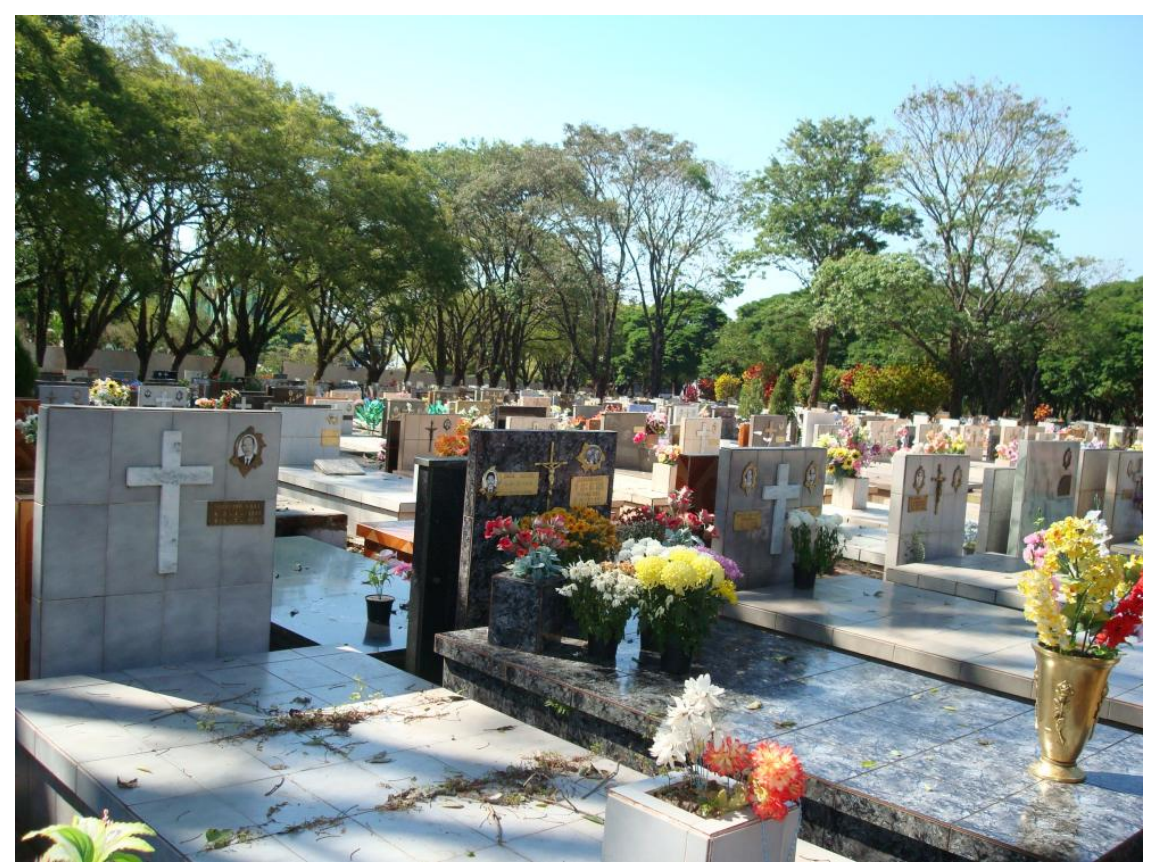

Figura 2 - Visualização de túmulos simples do cemitério jardim municipal

Fonte - os autores (2012)

No quarto parágrafo são dispostas as espessuras para o revestimento em cerâmica, cujas dimensões devem estar entre 0,06 e $0,08 \mathrm{~cm}$.

O quinto parágrafo do primeiro artigo, dispõe sobre revestimentos de outros materiais como o mármore e o granito estipulando as seguintes medidas para túmulos simples, duplos e jazigos de família: as laterais poderão ser de $2,0 \mathrm{~cm}$ de espessura, no entanto o tampão deverá ter, obrigatoriamente, $3,0 \mathrm{~cm}$ de espessura sendo este uma peça única.

Os artigos $2^{\circ}$ e $3^{\circ}$ deste Decreto também ficam estabelecidos que, quando se tratar de sepulturas antigas e sua construção fora realizada fora dos padrões, como capelinhas, jardineiras, túmulos com laje, estas deverão ser padronizadas para que possam receber revestimentos; além de que, somente serão concedidas à colocação de vasos de cerâmicas se estes não encontrarem-se fixados tanto no piso quanto nas laterais das sepulturas visando a não interrupção da circulação de pessoas. 
O artigo $4^{\circ}$ refere-se à pavimentação do terreno destinado à calçada dos carneiros, priorizando um limite máximo de $50 \%$ do espaço existente entre as sepulturas e que estas não poderão ultrapassar a altura do nível do meio fio.

Partindo para a configuração tumular de suas atuais 60 quadras, verificou-se que $60 \%$ dessas são caracterizadas por apresentarem apenas túmulos simples que podem ser verificados na Figura 2, isto é, túmulos onde só pode ocorrer uma inumação.

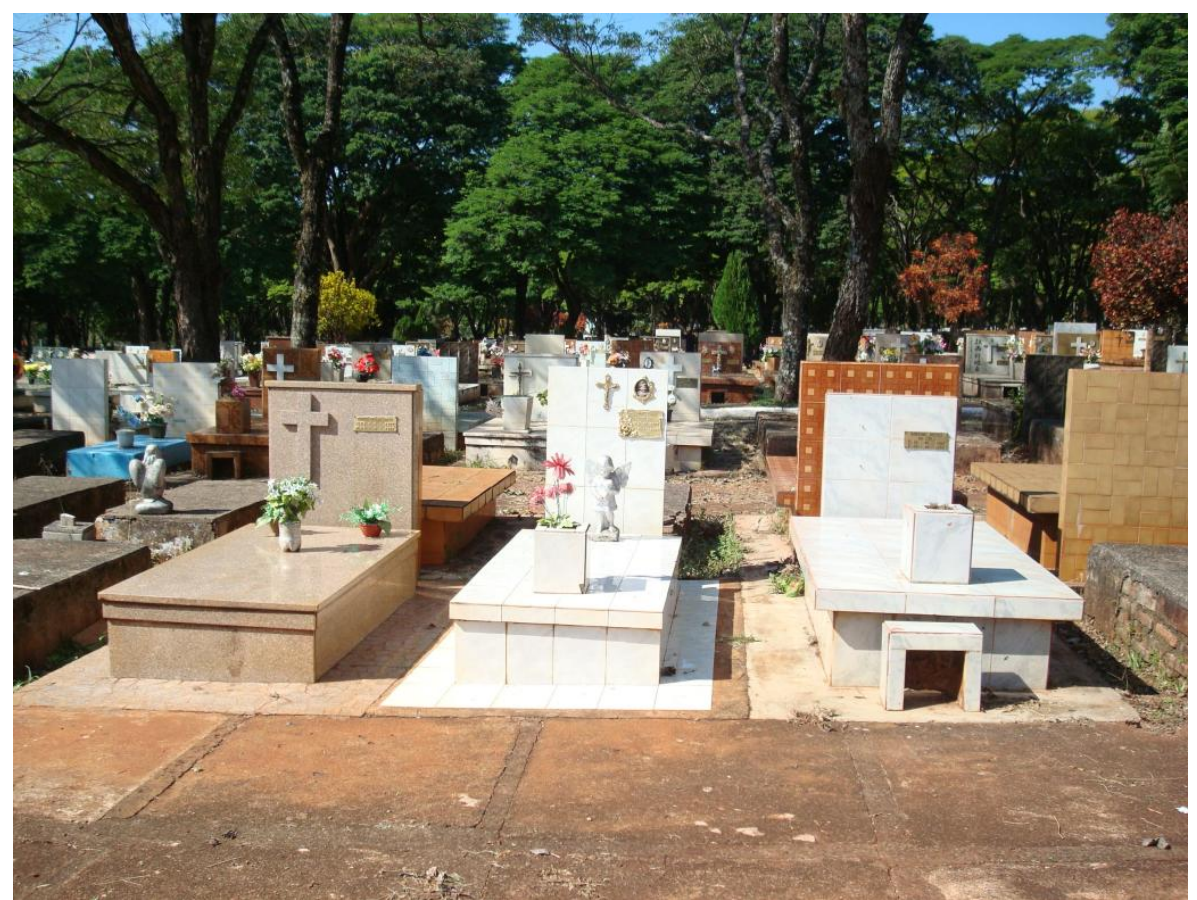

Figura 3 - Visualização de túmulos infantis do cemitério

Fonte - os autores (2012)

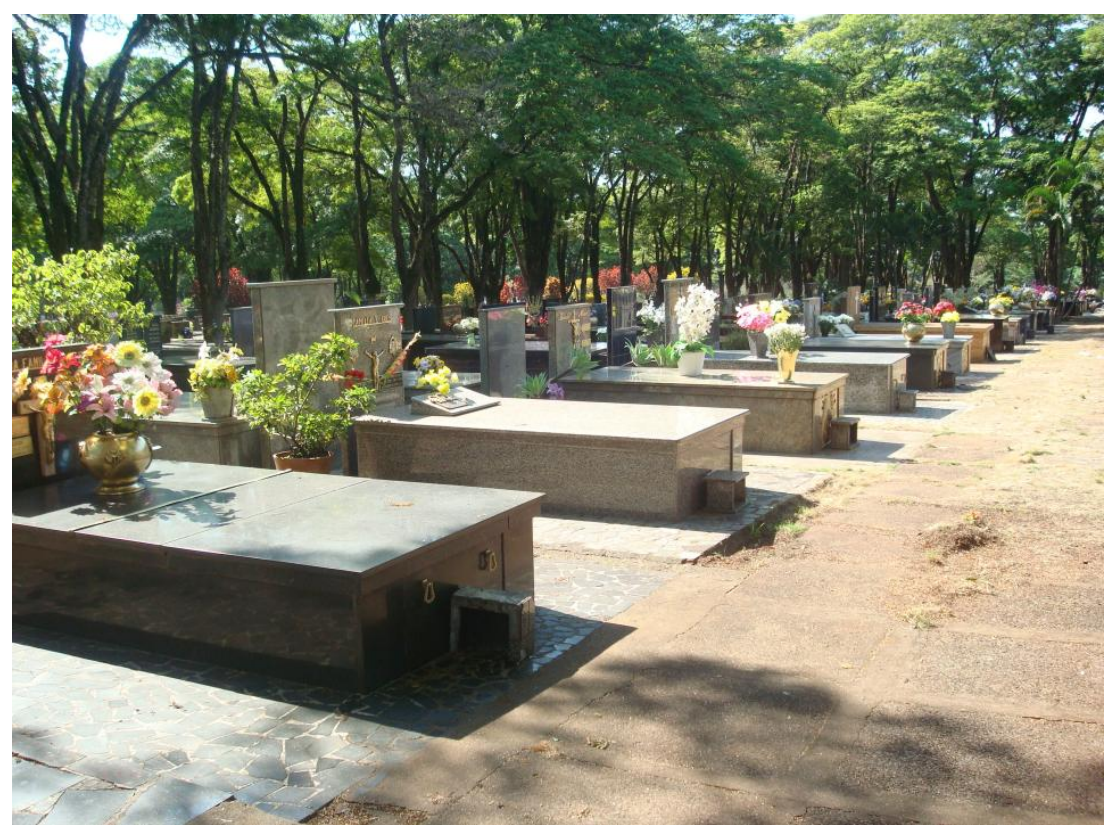

Figura 4 -Visualização de jazigos do cemitério jardim municipal

Fonte - os autores (2012) 


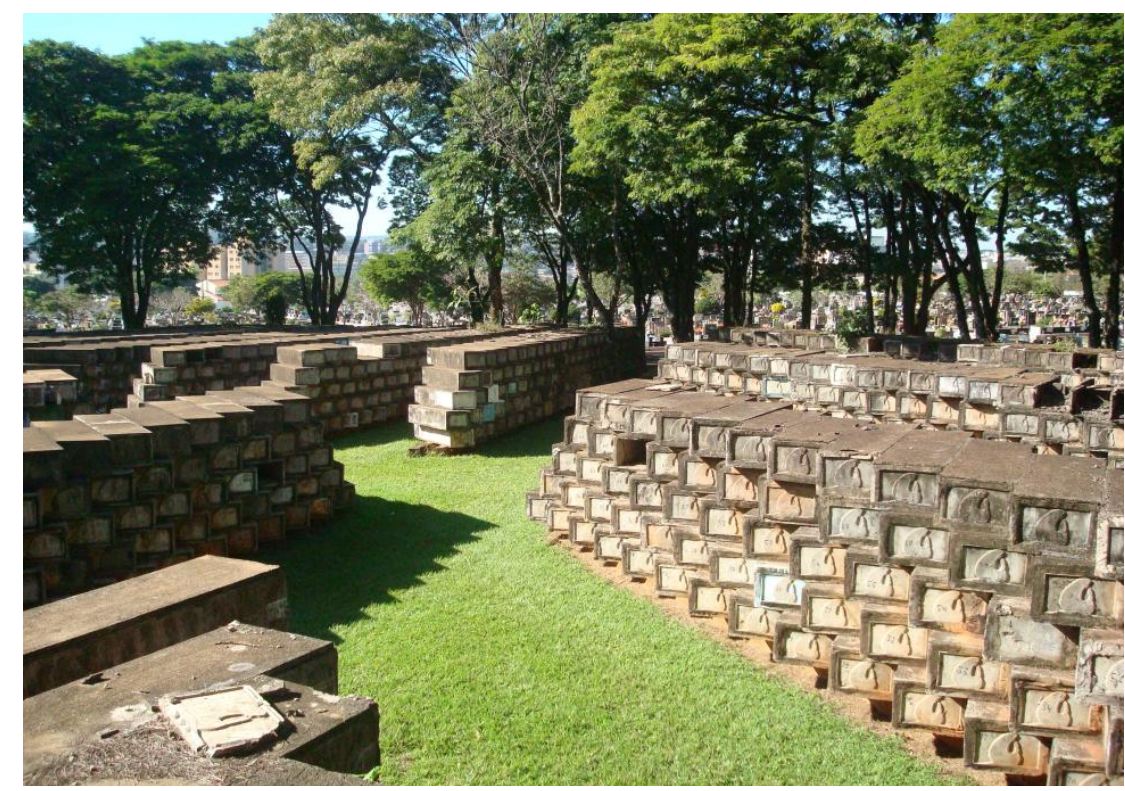

Figura 5 -Visualização do ossuário individual de Cemitério

Fonte - os autores (2012)

As quadras que apresentam sepulturas caracterizadas como duplas, ou seja, onde podem ocorrer até 2 inumações perfazem $22,7 \%$.

Nas quadras 26 e 42 estão localizados os túmulos infantis, que podem ser visualizados na Figura 3, bem como a quadra 13 que apresenta 3 linhas de túmulos destinados à inumação de crianças.

á as quadras 27 e 28 são apresentam sepulturas com capacidade para 6 inumações e 6 ossuários. Estas são caracterizadas por serem jazigos de família, que podem ser verificados na Figura 4.

As quadras 58 e 60 embora contemplem túmulos duplos, não estão completas, ou seja, ainda pode atender inumações, isto porque a administração do cemitério intercala nas mesmas essas inumações.

A quadra 59, potencialmente será reestruturada uma vez que esta apresenta "covas rasas", de onde os restos mortais de inumações realizadas a mais de 10 anos. Casos desta quadra como um todo, serão levados ao ossuário localizado na quadra 37 e que pode ser visualizado na Figura 5.

Saliente-se que o Cemitério Jardim de Maringá, não apresenta a quadra 16, devido ao fato desta ter sido desativada. Contudo, no espaço onde esta se encontrava atualmente localiza-se as capelas de velório do mesmo.

Ainda quanto às sepulturas, verificou-se a presença de túmulos e carneiros geminados (com as mesmas dimensões dos carneiros simples verificados nas quadras). Estes às margens do muro localizado na Avenida Juscelino Kubickec, como pode ser visualizado na Figura 6.

Estes, segundo o auxiliar administrativo e coordenador do cemitério, Sr. Carlos Aparecido Parolin, em entrevista realizada no dia 17/05/2012, são destinados a falecidos sem condições financeiras para adquirir uma sepultura. Ainda, em virtude do Decreto 100/1984 (PMM, 1984), o cemitério passou por inúmeras intervenções.

Destas, as mais importantes estão não só na tentativa de padronizar os túmulos anteriores às décadas de 1980, como também na estruturação das ruas que, a partir do citado Decreto, passaram a ser mais largas e retas, como pode ser verificado na Figura 7.

Partindo para uma análise mais específica em relação às sepulturas do Cemitério Jardim, pôde-se notar nas primeiras quadras deste, onde as inumações ocorriam sem a regulamentação e o devido ordenamento mencionado nos Decretos municipais trabalhados, que a construção dos túmulos, bem como a ornamentação destes, eram realizados de acordo com os anseios familiares do finado.

Estes anseios pautavam-se principalmente em projetar no túmulo, que seria a última morada do ente falecido, características muito próximas do que este tinha em sua vida terrena, como também de suas tradições materiais e espirituais, afim de que se sentissem à vontade, não apenas do ente falecido, mas dos remanescentes, quando da realização do culto ao seu morto. 


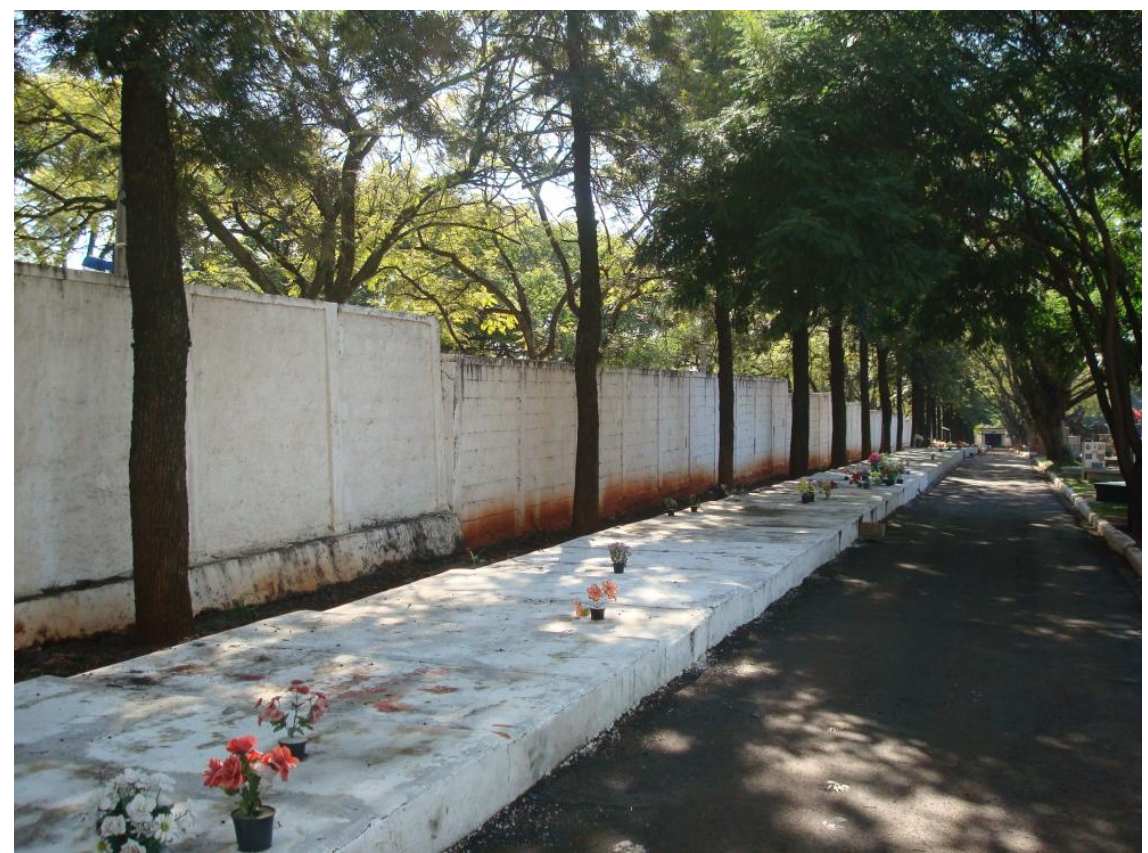

Figura 6 - Visualização dos Carneiros comunitários do cemitério Fonte - os autores (2012)

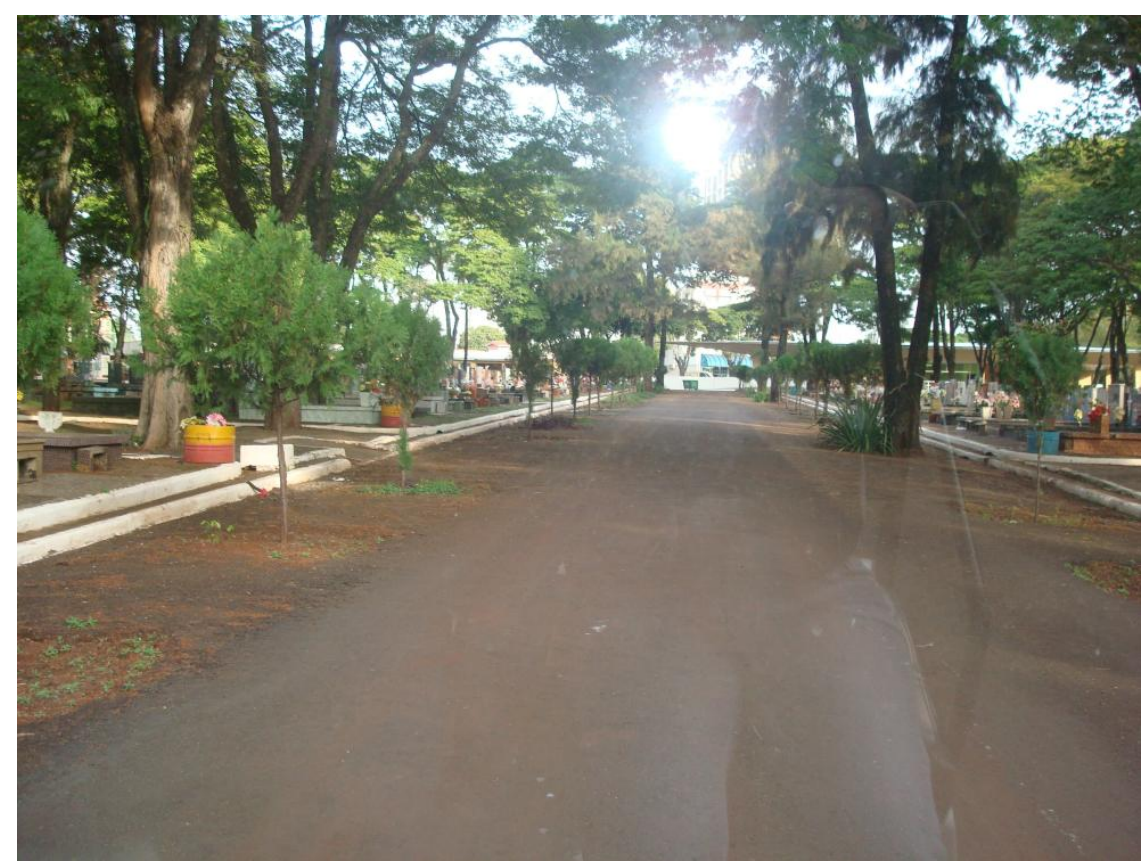

Figura 7 -Visualização parcial de uma das ruas estruturadas do cemitério

Fonte - os autores (2012)

A partir destas constatações em cemitérios paulistas Cymbalista (2002) cita que neste contexto, a arquitetura é explorada em toda a sua potencialidade, para produzir a identificação e a diferença, seduzindo, intimidando, propondo novas e velhas maneiras de se representar a morte e os próprios mortos.

Assim, cada família projetando o túmulo de seu ente, foi ao longo das décadas de 1950, 60, 70 e inicio de 80 produzindo a paisagem atual do Cemitério Jardim Municipal. Deste modo, a somatória no espaço e no acúmulo do tempo dessas inúmeras escolhas produz a paisagem do cemitério.

Tal projeção arquitetônica passa ao longo do tempo por influências culturais como a utilização do Mármore Carrara, caso do primeiro túmulo verificado no cemitério (Figura 1), como também pela 
utilização da engenharia na construção de túmulos capelas na quadra 02 , como pode ser visualizado na Figura 8, além da presença de objetos com altos apelos simbólicos como as cruzes maltinas, os vasos, as estátuas, as inscrições e ainda as pinturas sacras nas quadras 03, 04 e 07, que pode ser verificado na Figura 9.

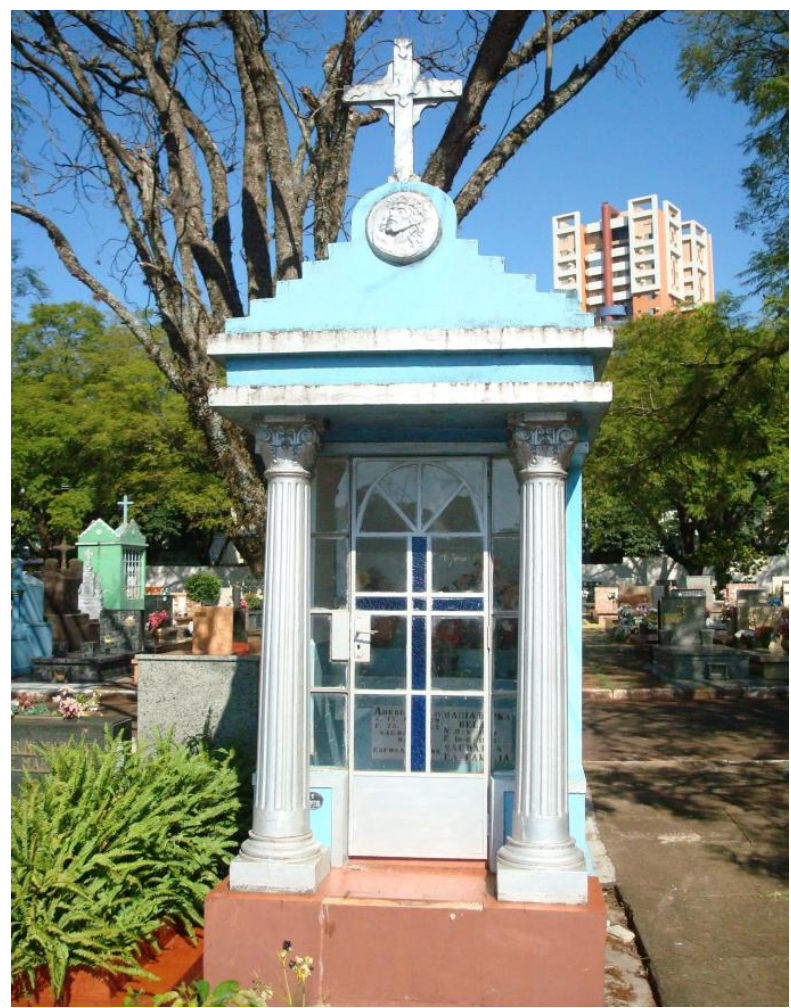

Figura 8 - Visualização de túmulo capela no cemitério jardim municipal Fonte - os autores (2012)

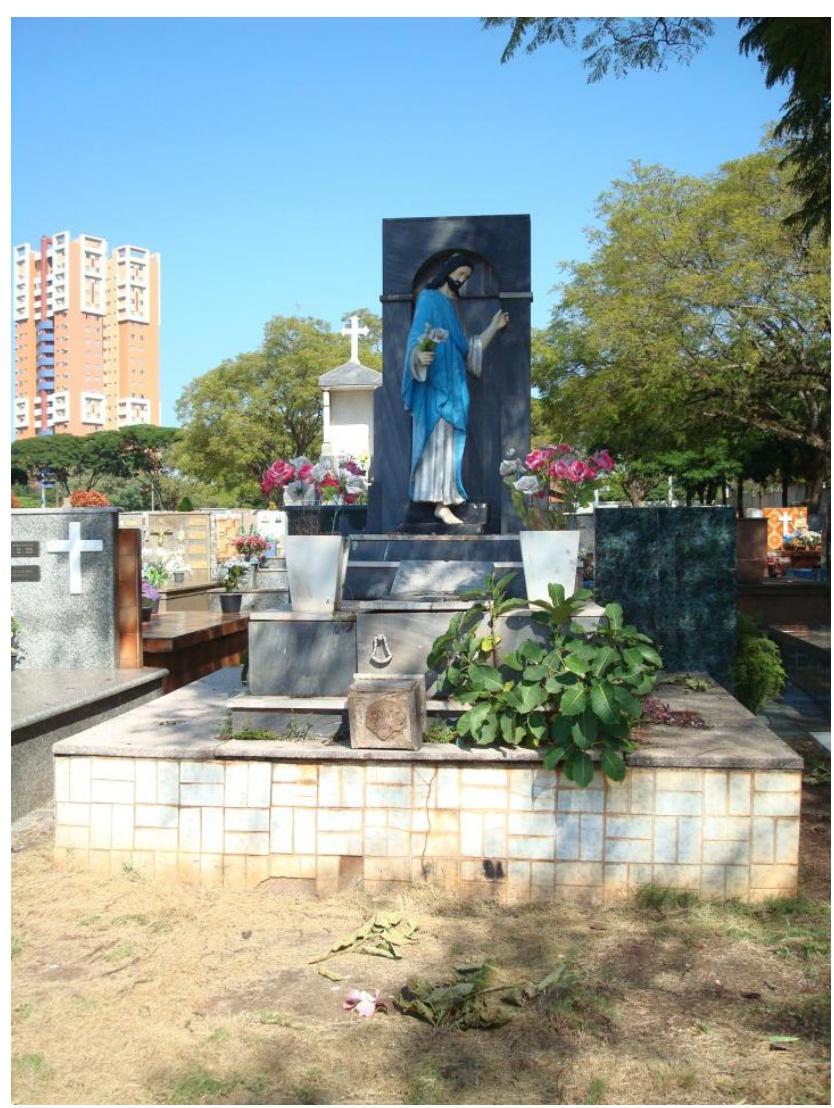

Figura 9 - Visualização de túmulo com vasos e estátuas sacras no cemitério jardim municipal Fonte - os autores (2012)

REGET - V. 20, n. 1, jan.- abr. 2016, p.475-486 
Fol (2013) tece as seguintes considerações quanto ao simbolismo dos seguintes objetos: "A Cruz Latina, simboliza a paixão de Cristo. Conforme a tradição representa o local em que Cristo foi crucificado e é símbolo da sorte e da esperança. Muito usada em todos os tipos de túmulos, é atributo de inúmeros santos como Santa Helena e São Jorge".

Já o vaso, ainda segundo Fol (2013), simboliza o corpo separado da alma (vaso vazio); a eterna felicidade (vaso com um pássaro pousado em sua borda, saciando a sede); a Anunciação (vaso com lírio); e a glória e a paz (vaso com óleo santo).

Esses comportamentos podem ser verificados, por exemplo, nas primeiras quadras do cemitério, construídas antes da regulamentação do Decreto 100/1984, onde os sepulcros demonstram todo o anseio dos familiares (responsáveis na época pela construção das sepulturas), em transpor para estes, que são a ultima morada de seus entes, um pouco do que estes passaram em vida.

Deste modo, nas primeiras quadras do Cemitério Jardim Municipal há muitos túmulos capelas, com imagens Sacras, o que demonstra características da década de 50, 60 e 70 baseada na agricultura cafeeira e que, de certo modo, recebeu influencia da arquitetura tumular verificada no Cemitério da Consolação em São Paulo onde se encontram enterrados inúmeros Barões do Café, bem como toda a religiosidade dos imigrantes em sua grande maioria italianos que fixaram residência no noroeste do Paraná.

Já após a década de 80, com a padronização das sepulturas, a arquitetura dos túmulos demonstra que a sociedade primou por tornar a cidade dos mortos um local sem distinções e igualitário, tendo em vista que, como já dito, foram normatizados tanto o tamanho, comprimento e largura das sepulturas quanto os materiais que potencialmente podem ser usados no revestimento destas.

Outro indicativo dessa busca pela igualdade é o fato de que a partir do Decreto 100/1984, nenhum sepultamento pode ocorrer em cova rasa. Deste modo, as famílias sem condições financeiras de comprar um lóculo no cemitério têm a possibilidade de enterrar o ente em carneiros comunitários.

Ressalte-se, contudo, que estes túmulos não são perpétuos, isto é, eles são túmulos onde após três anos (tempo regulamentado pela Legislação Ambiental do Estado do Paraná, para exumação de corpos), os restos mortais ("ossos"), são exumados e levados ao ossuário individual localizado na quadra 37.

Quanto à gestão administrativa do cemitério, torna-se coerente citar que o mesmo é regido por diretrizes estipuladas no Plano Diretor Municipal. Contudo, em virtude dos cemitérios serem considerados por inúmeros autores, como Cymbalista (2002), Matos (2001) e Pacheco e Batelo (2000), a cidade dos mortos, há existência de um plano diretor específico para estes.

\section{CONCLUSÃO}

Dessa forma pode-se afirmar que a paisagem verificada no Cemitério Jardim Municipal de Maringá, transparece todo o ideário, toda cultura da sociedade maringaense, bem como reflete toda uma sequência de atitudes que foram tomadas pelos administradores do cemitério e do município no que se refere a manter uma padronização quanto à arquitetura tumular.

A paisagem transparece o ideário e a cultura da sociedade maringaense a partir do momento que as sepulturas do Cemitério Jardim refletem os vários comportamentos que a sociedade do município teve ao longo dos anos.

No caso do Cemitério Municipal de Maringá a existência de um Plano Diretor específico seria importante, tendo em vista que, aspectos como resíduos, padronização de espécies arbóreas, iluminação de vias, bem como esgotamento pluvial, seriam melhor gerenciados promovendo uma paisagem integralizada e que promovesse, efetivamente, um ambiente harmonioso para os visitantes. 
Martim et al.: Análise da arquitetura tumular do cemitério jardim municipal...

\section{AGRADECIMENTOS}

Ao Senhor Carlos Aparecido Parolin, auxiliar administrativo e coordenador do cemitério.

\section{REFERÊNCIAS}

ALMEIDA, A.M. Análise físico-química das águas próximas a alguns cemitérios no município de Juiz de Fora. 2004. 10p. Trabalho de Conclusão de Curso (Graduação) - Universidade Federal de Juiz de Fora / Departamento de Química, Juiz de Fora - MG - Brasil.

BRASIL. Resolução Federal 357 de 17 de março de 2005. CONAMA - Conselho Nacional de Meio Ambiente. Dispõe sobre a conservação dos recursos hídricos. Disponível em: http//www.meioambiente.gov.br e acessado em 14 fev. 2012.

Lei Federal n 6.938, de 31 de agosto de 1981. Disponível em: http://www.planalto.gov.br/ccivil 03/Leis/L6938.htm e acessado em 15 fev. 2012.

CETESB - Companhia de Tecnologia de Saneamento Ambiental. Norma 15.011/1992 - Sistema para Incineração de Resíduos de Serviço de Saúde, Portos e Aeroportos. Disponível em http://www.ambiente.sp.gov.br/wp-content/uploads/cea/Res.SS-SMA-SJDC01-04.pdf e acessado 13 fev. 2012. CETESB, 1992.

CYMBALISTA, R. Cidade dos Vivos - Arquitetura e atitudes perante a morte nos cemitérios do estado de São Paulo. São Paulo: Annablume; Fapesp, 2002.

FOL. Entendendo a arte de tumular. Disponível em http://www.funerariaonline.com.br/Dicas/ Imprimir.asp?idnews=4068 e acessado em 02 mar 2013

MATOS, B.A. Avaliação da ocorrência e do transporte de microrganismos no aquífero freático do cemitério de Vila Nova Cachoeirinha, município de São Paulo. São Paulo - SP: Universidade de São Paulo - Instituto de Geociências. Tese de Doutoramento, 2001.

PACHECO, A.; BATELO, E. A influência de fatores ambientais nos fenômenos transformativos em cemitérios. Revista de Engenharia e Arquitetura, v.2, n.1, p 32-39, 2000.

PARANÁ. RESOLUÇÃO ESTADUAL 019/06: Dispõe sobre o licenciamento ambiental de cemitérios horizontais: Curitiba, 04 de maio de 2004.

RESULUÇÃO ESTADUAL 016/05: Dispõe sobre o licenciamento ambiental de cemitérios horizontais: Curitiba, 03 de outubro de 2005.

PMM - PREFEITURA MUNICIPAL DE MARINGÁ. DECRETO N 100/1984: Aprova o regulamento do cemitério jardim municipal de Maringá: Maringá, 27 de Abril de 1984.

-. DECRETO N 1.475/2002: Regulamenta o revestimento e reconstruções de sepulturas do cemitério jardim municipal de Maringá: Maringá, 18 de outubro de 2002.

ROMANINI, E.C.O.; MOREIRA, F.B.; MONTES FILHO, C.H.M.; MOREIRA, M. Expressões através dos símbolos tumulares no cemitério municipal Padre Rodolfo Kumoreck da cidade de São José dos Campos. IX Encontro Latino Americano de Iniciação científica e V Encontro Latino Americano de Pós-Graduação - Universidade do Vale do Paraíba, 2004. 
SILVA, L.M. Cemitérios: fonte potencial de contaminação dos aquíferos livres. In: CONGRESSO LATINO AMERICANO DE HIDROLOGIA SUBTERRÂNEA，4，1998， Montevidéu. Anais... Memórias. Montevidéu: ALHSUD. v. 2, p. 667-681. (1998).

SILVA, V.T.; CRISPIM, Q.; et al. Um Olhar Sobre as Necrópoles e seus Impactos Ambientais. In: Encontro da ANPPAS, N 3, 2006, Brasília. Anais. Brasília: Editora da Universidade Nacional de Brasília - UNB.

VALADARES, C.P. Arte e sociedade nos cemitérios brasileiros: um estudo da arte cemiterial ocorrida no Brasil desde as sepulturas de igrejas e as catacumbas de ordens e confrarias até as necrópoles secularizadas. Rio de Janeiro: Conselho Federal de Cultura, 1972, v.1, p.36. 